\title{
Incidence and risks for surgical site infection after closed tibial plateau fractures in adults treated by open reduction and internal fixation: a prospective study
}

\section{Junyong $\mathrm{Li}$}

Hebei Medical University Third Affiliated Hospital

Yanbin Zhu

Hebei Medical University Third Affiliated Hospital

Kuo Zhao

Hebei Medical University Third Affiliated Hospital

Junzhe Zhang

Hebei Medical University Third Affiliated Hospital

Hongyu Meng

Hebei Medical University Third Affiliated Hospital

Zhucheng Jin

Hebei Medical University Third Affiliated Hospital

Jiangtao Ma

Hebei Medical University Third Affiliated Hospital

Yingze Zhang ( $\square$ suryzz@163.com )

\section{Research article}

Keywords: closed tibial plateau fractures, surgical site infection, incidence, risk factors

Posted Date: May 12th, 2020

DOI: https://doi.org/10.21203/rs.3.rs-26671/v1

License: (c) (1) This work is licensed under a Creative Commons Attribution 4.0 International License. Read Full License

Version of Record: A version of this preprint was published on August 24th, 2020. See the published version at https://doi.org/10.1186/s13018-020-01885-2. 


\section{Abstract \\ Background}

Surgical site infection (SSI) was the most common complication of tibial plateau fracture after open reduction and internal fixation (ORIF). Severe infections even required repeat surgeries, which would cause serious psychological harm to patients and increased the economic burden of treatment. In order to identify the characteristics of the SSI and to avoid the occurrence of SSI, we conducted a prospective study to investigate the incidence and independent risk factors of SSI after ORIF for closed tibial plateau fractures in adults.

\section{Methods}

This study was performed at a first-level trauma center. From October 2014 to December 2018, the study subjects were adult patients with closed fractures of the tibial plateau, all of whom underwent open reduction and internal fixation (ORIF) treatment. Finally, a total of 1108 patients were followed up. We collected patient demographics information, surgery-related variables and indexes from pre-operative laboratory examinations. Univariate and multivariate logistic analysis models were used to investigate the potential risk factors.

\section{Results}

Twenty-five patients $(2.3 \%, 25 / 1108)$ developed SSI. A total of 15 of 25 infections $(60.0 \%)$ were due to Staphylococcus aureus and $3(12.0 \%)$ were due to MRSA. Independent risk factors of SSI identified by multivariate logistic analysis model were bone grafting: autograft $(\mathrm{OR}, 6.38 ; 95 \% \mathrm{Cl}, 2.155-18.886 ; p=$

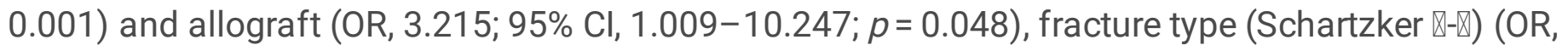
8.129; 95\% Cl, 2.961-22.319; $p<0.001)$, aspartate aminotransferase ( $40 \mathrm{U} / \mathrm{L})(\mathrm{OR}, 5.500 ; 95 \% \mathrm{Cl}$, 2.191-13.807; $p<0.001)$, white blood cell (>10*10\% /L) (OR, 2.498; 95\% Cl, 1.025-6.092; $p=0.044)$, and anion gap (>16 mmol/L) (OR, 8.194; 95\% Cl, 1.101-60.980).

\section{Conclusions}

We should pay enough attention to patients who carried one or more of these factors at admission and adopt more reasonable treatment strategies to reduce or avoid the occurrence of SSI.

\section{Introduction}

Tibial plateau fracture was one of the most common lower limb fractures in orthopedics, accounting for $36.5 \%$ of tibial and fibula fractures[1]. Tibial plateau was the weight-bearing area of the knee joint, if not treated properly, it would cause serious consequences. By far, ORIF is the most commonly treatment 
choice, which aims at anatomical reduction of fractures and restoration of lower limb force line. However, there were many potential complications of surgical treatment after tibial plateau fracture, including SSI, joint stiffness, traumatic osteoarthritis, delayed or non-union.[2-4], Among the complications, SSI was the most common one. Previous literature had reported that SSIs developed at $2-14.2 \%$ of patients after they underwent ORIF, half of which were deep infections[5-7]. Consequently, patients had to be readmitted, or even re-operated to replace or remove internal fixtures to treat the infection. Moreover, severe infections even required repeat surgeries, which would cause serious psychological harm to patients and increased the economic burden of treatment. Therefore, prevention of postoperative infection was far more important than treatment of postoperative infection itself. Accordingly, it was important to understand the characteristics and associated risk factors of SSI to reduce this complication.

Previous studies had been conducted to investigate the incidence and related risk factors of SSI, including the extended operation time, smoking status, open fracture type, higher level of fracture type (Schatzker types IV-VI), and so on [5-8]. However, most previous researched were designed as retrospective, which might have limitations inaccuracy of data collection and obscure follow-up information.

Given the above, we designed this prospective study to describe the incidence and characteristics of SSI and to identify independent risk factors associated with SSI.

\section{Patients And Methods}

Data used in this study were extracted from the database of Surgical Site Infection in Orthopaedic Surgery (SSIOS), in which a prospective method was used to collect data on patients who underwent orthopaedic surgeries between October 12014 and December 31 2018. In SSIOS study, surveillance of surgical site during hospitalization and telephone follow-up after discharge were conducted to identify surgical site infections.

In this study, the inclusion criteria were all adult patients ( $\geq 18$ years) with closed tibial plateau fractures treated with ORIF. Multiple trauma patients were also included. Exclusion criteria were under 18 years of age, open fractures, pathological fractures caused by other diseases, treatment with external fixation or conservative method, incomplete medical data, patients lost to follow-up, and fractures around the prosthesis after knee replacement.

In order to accurately analyze the factors of postoperative infection, from the beginning we collected as much information as possible about the patient, including patients' demographics information, the preoperative evaluation, and the various indicators during the operation. We set up a well-trained team to collect the detailed information of each patient every day. Investigators visited the ward regularly, followed the patients closely, questioned them, looked at their medical records and charts, recorded the variables of interest, and examined the suture site for signs of infection since the day after the surgery. After discharge, all patients underwent regular telephone follow-up at postoperative 3, 6, 12 months to determine the presence of SSI. 


\section{Data Collection Of Variables}

Patients' demographics information including age, gender, height, weight, chronic diseases (diabetes mellitus, hypertension, cerebrovascular disease, chronic heart disease), living places (rural or urban), history of any surgery, allergy to any medications, smoking status, alcohol consumption were extracted and documented.

Body Mass Index (BMI) was divided into four groups using Chinese standards: normal, 18.5-23.9; underweight, $<18.5$; overweight, 24-27.9; obesity and morbid obesity, $\geq 28$.

Characteristics of fractures included injury mechanism (low or high-energy), side involved, combined injuries and fracture classification (Schatzker classification system). Fall from a standing height was defined as a low-energy injury, and fall from a height, traffic accident, and a sports injury was defined as a high-energy injury.

Surgery-related variables included ASA grade (American Society of Anesthesiologists), preoperative duration, anesthesia pattern, operative duration, fixation type, intraoperative blood loss, intraoperative blood transfusion, bone grafting, intraoperative and postoperative intravenous use of antibiotic.

Preoperative duration was defined as time from injury to surgery, and was divided into two groups: $1, \leq 7$ days and 2,囚7 days. Anesthesia pattern was divided into regional anesthesia and general anesthesia. Operative duration was also divided into two groups: $1, \leq 120$ minutes and 2,8120 minutes. Intraoperative blood loss was divided into two groups: $1, \leq 400 \mathrm{ml}$ and 2, $₫ 400 \mathrm{ml}$. Bone grafting pattern was divided into autograft and allograft. Prophylactic antibiotics were administered intravenously 30 minutes before surgery according to guidelines[9].

We recorded the values of pre-operative laboratory examinations and divided them into normal, higher or lower than normal. These variables included platelet (PLT), albumin/globulin (A/G), alanine transaminase (ALT), neutrophils (NEUT), white blood cells (WBC), red blood cell (RBC), albumin (ALB), total cholesterol (TC), aspartate aminotransferase (AST), low density lipoprotein (LDL-C), hematatocrit (HCT), lactate dehydrogenase (LDH), monocytes (MON), mean corpuscular hemoglobin (MCH), lymphocytes (LYM), hydroxybutyrate dehydrogenase $(\mathrm{HBDH})$, triglyceride $(T G)$, high density lipoprotein (HDL-C), very lowdensity lipoprotein (VLDL), y-glutamyl transpeptidase (GGT), mean corpuscular volume (MCV), osmotic pressure (OSM), indirect bilirubin (IBIL), serum urea (UREA), uric acid (UA), hemoglobin (HGB), red cell distribution width (RDW), hypersensitive c-reactive protein (HCRP), platelet distribution width (PDW), glucose (GLU), mean corpuscular hemoglobin concentration (MCHC), total protein (TP), globulin (GLOB), anion gap (AG), aspartate total bilirubin (TBIL), direct bilirubin (DBIL), alkaline phosphatase (ALP), cholinesterase (CHE), total bile acid (TBA).

\section{Definition Of SSI}


SSI was defined based on the standards of Center for Disease Control (CDC)[10]. Fascia or muscle infections, skin dehiscence or persistent wound secretions, visible abscesses or gangrene requiring surgical debridement and implant exchange or removal were considered deep SSI. Infections limited to the skin of the surgical site, not exceeding the depth of the subcutaneous tissue, with common surgical incision problems (redness, swelling, pain) that could be cured by oral or intravenous antibiotics are considered superficial infections.

\section{Statistical analysis}

For continuous variables, Student t-test and Mann-Whitney U-test were used (depending on whether the value of the variable is normally distributed), and the significance was $p<0.05$. First, a univariate logic analysis was used to evaluate the relationship between each categorical variable and SSI. Then the variables that were tested as significant in the univariate analyses to predict SSI were included in the multivariate logistic regression analysis model, and the independent predictors of SSI were finally determined. The goodness of fit of the model was tested using Hosmer-Lemeshow. $p>0.05$ was an acceptable goodness of fit.

\section{Results}

\section{Characteristics of the study sample}

During the study interval, a total of 1384 patients with tibial plateau fracture were collected, 236 patients were excluded due to age less than 18 years (49), periprosthetic fracture (13), pathological fracture (14), open fracture (71), treatment with external fixation or conservative method (60), incomplete medical data (29) and patients lost to follow-up (40) (Fig. 1). Finally, 1108 patients were included in the final analysis, with a mean age of 45.6 years (range, 18 to 82). There were 697 males and 411 females, with left side involved in 590 and right side in 518 cases.

\section{Characteristics Of SSI}

During the follow-up period, 25 (2.3\%) patients developed SSI after ORIF. Among them, 4 cases were cured by intravenous antibiotics and conventional local wound care, 12 cases were debrided in the operating room, and 9 cases were debrided combined with internal fixation hardware removal. The earliest diagnosis of SSI occurred on the 3 days post-operation, the latest on the 300 days, with a median time of 7 days. Each patient underwent wound secretion bacterial culture. Staphylococcus aureus was the most common causative pathogen $(15,60.0 \%)$, of which 3 cases $(3,12.0 \%)$ were MASA, followed by escherichia coli $(3,12.0 \%)$, enterobacter cloacae $(2,8.0 \%)$, acinetobacter baumannii $(1,4.0 \%)$, pseudomonas aeruginosa $(1,4.0 \%)$, multi-bacterium $(1,4.0 \%)$, and no pathogenic bacteria were cultured in 2 cases $(2,8.0 \%)$. 
Statistically significant demographical and perioperative variables, such as age (45.6 versus 43.0 years, $p=0.347$ ), preoperative stay (7.3 versus 14.5 days, $p<0.001)$, intraoperative blood loss ( 280.2 versus $434.0 \mathrm{ml}, p=0.005$ ), operation duration ( 147.4 versus 195.8 minutes, $p<0.001$ ), and hospital stay (19.3 versus 43.4 days, $p<0.001$ ), were presented in Table 1 . In term of other variables, there was no significant difference between the SSI group and the non-SSI group. SSI prolonged a mean of 24.1 days of hospitalization than that of non-SSI.

Table 1

Comparison of continuous variables in patients with and without SSI

\begin{tabular}{|lllr|}
\hline Variables & $\begin{array}{l}\text { Patient without SSI (mean, } \\
\text { standard deviation) }(\mathbf{n = 1 0 8 3 )}\end{array}$ & $\begin{array}{l}\text { Patient with SSI (mean, } \\
\text { standard deviation) }(\mathbf{n}=25)\end{array}$ & $P$ \\
\hline Age (years) & $45.6(13.6)$ & $43.0(11.8)$ & 0.347 \\
\hline $\begin{array}{l}\text { Preoperative stay } \\
\text { (days) }\end{array}$ & $7.3(6.9)$ & $14.5(17.9)$ & $0.000^{*}$ \\
\hline $\begin{array}{l}\text { Intraoperative } \\
\text { blood loss (ml) }\end{array}$ & $280.2(267.4)$ & $434.0(370.7)$ & $0.005^{*}$ \\
\hline $\begin{array}{l}\text { Operation } \\
\text { duration } \\
\text { (minutes) }\end{array}$ & $147.4(64.7)$ & $195.8(68.4)$ & $0.000^{*}$ \\
\hline $\begin{array}{l}\text { Hospital stay } \\
\text { (days) }\end{array}$ & $19.3(22.5)$ & & $0.000^{*}$ \\
\hline
\end{tabular}

\section{Univariate And Multivariate Analysis}

Factors that significantly increased the risk of SSI in univariate analysis are summarized in Table 2, including patients' demographics information, BMI, Surgery-related variables, the values of pre-operative laboratory examinations. 
Table 2

Univariate analyses of risk factors associated with SSI after ORIF of closed tibial plateau fracture

\begin{tabular}{|c|c|c|c|}
\hline Variables & $\begin{array}{l}\text { Number }(\%) \text { of } \\
\text { SSI }(n=25)\end{array}$ & Number $(\%)$ of non-SSI $(n=1083)$ & $P$ \\
\hline Gender (male) & $20(80.0)$ & $677(62.5)$ & 0.074 \\
\hline Diabetes mellitus & $2(8.0)$ & $150(13.8)$ & 0.401 \\
\hline Hypertension & $2(8.0)$ & $197(18.2)$ & 0.189 \\
\hline Cerebrovascular disease & $1(4.0)$ & $18(1.7)$ & 0.373 \\
\hline Chronic heart disease & $1(4.0)$ & $51(4.7)$ & 0.868 \\
\hline History of any surgery & $1(4.0)$ & $118(10.9)$ & 0.271 \\
\hline Allergy to any medications & $3(12.0)$ & $138(12.7)$ & 0.912 \\
\hline Living area & & & 0.827 \\
\hline Rural & $15(60.0)$ & $673(62.1)$ & \\
\hline Urban & $10(40.0)$ & $410(37.9)$ & \\
\hline Preoperative duration (days) & & & $0.000^{*}$ \\
\hline $1-7$ & $8(32.0)$ & $723(66.8)$ & \\
\hline$>7$ & $17(68.0)$ & $360(33.2)$ & \\
\hline Anesthesia (general) & $10(40.0)$ & $450(41.6)$ & 0.876 \\
\hline Number of fracture & & & 0.057 \\
\hline 1 & $11(44.0)$ & $679(62.7)$ & \\
\hline$\geq 2$ & $14(56.0)$ & $404(37.3)$ & \\
\hline Mechanism (high-energy) & $17(68.0)$ & $676(62.4)$ & 0.569 \\
\hline Current smoking & $4(16.0)$ & $147(13.6)$ & 0.727 \\
\hline Alcohol consumption & $2(8.0)$ & $101(9.3)$ & 0.821 \\
\hline Bone grafting (yes) & $13(52.0)$ & $225(20.8)$ & $0.000 *$ \\
\hline Bone graft type & & & $0.000 *$ \\
\hline Autograft & $8(32.0)$ & $113(10.4)$ & \\
\hline Allograft & $5(20.0)$ & $112(10.3)$ & \\
\hline Operative duration (minutes) & & & $0.001^{\star}$ \\
\hline $1-120$ & $3(12.0)$ & $505(46.6)$ & \\
\hline
\end{tabular}




\begin{tabular}{|c|c|c|c|}
\hline Variables & $\begin{array}{l}\text { Number (\%) of } \\
\text { SSI }(n=25)\end{array}$ & Number $(\%)$ of non-SSI $(n=1083)$ & $P$ \\
\hline$>120$ & $22(88.0)$ & $578(53.4)$ & \\
\hline Intraoperative blood loss (ml) & & & $0.000 *$ \\
\hline $1-400$ & $15(60.0)$ & $931(86.0)$ & \\
\hline$>400$ & $10(40.0)$ & $152(14.0)$ & \\
\hline ASA class & & & 0.942 \\
\hline प & $3(12.0)$ & $155(14.3)$ & \\
\hline Q & $18(72.0)$ & $768(70.9)$ & \\
\hline \or above & $4(16.0)$ & $160(14.8)$ & \\
\hline Prophylactic antibiotics use & $22(88.0)$ & $1038(95.8)$ & 0.057 \\
\hline Postoperative antibiotics use & $22(88.0)$ & $1005(92.8)$ & 0.362 \\
\hline Fixation type & & & 0.774 \\
\hline Plate and screws & $23(92.0)$ & $1012(93.4)$ & \\
\hline Screws only & $2(8.0)$ & $71(6.6)$ & \\
\hline Intraoperative blood transfusion & $6(24.0)$ & $106(9.8)$ & $0.020 *$ \\
\hline Fracture type (Schartzker) & & & $0.000 *$ \\
\hline 凶-邓 & $6(24.0)$ & $835(77.1)$ & \\
\hline 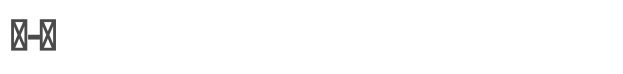 & $19(76.0)$ & $248(22.9)$ & \\
\hline Age (years) & & & 0.461 \\
\hline $18-44$ & $15(60.0)$ & $514(47.5)$ & \\
\hline $45-64$ & $8(32.0)$ & $462(42.7)$ & \\
\hline$\geq 65$ & $2(8.0)$ & 107 (9.9) & \\
\hline BMI $\left(\mathrm{kg} / \mathrm{m}^{2}\right)$ & & & 0.361 \\
\hline $18.5-23.9$ & $9(36.0)$ & $473(43.7)$ & \\
\hline$<18.5$ & $1(4.0)$ & $11(1.0)$ & \\
\hline 24-27.9 & $8(32.0)$ & $383(35.4)$ & \\
\hline$\geq 28.0$ & $7(28.0)$ & 216 (19.9) & \\
\hline TP (<60 g/L) & $11(44.0)$ & $285(26.3)$ & $0.048^{*}$ \\
\hline
\end{tabular}




\begin{tabular}{|c|c|c|c|}
\hline Variables & $\begin{array}{l}\text { Number }(\%) \text { of } \\
\text { SSI }(n=25)\end{array}$ & Number $(\%)$ of non-SSI $(n=1083)$ & $P$ \\
\hline ALB (<35 g/L) & $12(48.0)$ & $224(20.7)$ & $0.001 *$ \\
\hline GLOB (<20 g/L) & $4(16.0)$ & $157(14.5)$ & 0.833 \\
\hline A/G values & & & $0.009 *$ \\
\hline $1.2-2.4$ & $18(72.0)$ & $970(89.6)$ & \\
\hline$<1.2$ & $6(24.0)$ & $81(7.5)$ & \\
\hline$>2.4$ & $1(4.0)$ & $32(3.0)$ & \\
\hline ALT (> $40 \mathrm{U} / \mathrm{L})$ & $12(48.0)$ & $199(18.4)$ & $0.000 *$ \\
\hline AST (> $40 \mathrm{U} / \mathrm{L})$ & $11(44.0)$ & $140(12.9)$ & $0.000 *$ \\
\hline TBIL (> 21 umol/L) & $4(16.0)$ & $91(8.4)$ & 0.180 \\
\hline DBIL (> 6 umol/L) & $9(36)$ & $302(27.9)$ & 0.372 \\
\hline IBIL (> 14 umol/L) & $6(24)$ & $162(15.0)$ & 0.213 \\
\hline ALP $(>100 \mathrm{U} / \mathrm{L})$ & $3(12.0)$ & $50(4.6)$ & 0.087 \\
\hline GGT (>60 U/L) & $7(28.0)$ & $183(16.9)$ & 0.145 \\
\hline CHE (> $12 \mathrm{KU} / \mathrm{L})$ & $1(4.0)$ & $27(2.5)$ & 0.635 \\
\hline TBA (> 10 umol/L) & $2(8.0)$ & $65(6.0)$ & 0.679 \\
\hline $\mathrm{HCRP}(>8 \mathrm{mg} / \mathrm{L})$ & $17(68.0)$ & $732(67.6)$ & 0.965 \\
\hline LDH (> $250 \mathrm{U} / \mathrm{L})$ & $10(40.0)$ & $244(22.5)$ & $0.040^{*}$ \\
\hline HBDH (> 182 U/L) & $5(20.0)$ & $183(16.9)$ & 0.683 \\
\hline $\mathrm{TC}(>5.2 \mathrm{mmol} / \mathrm{L})$ & $1(4.0)$ & $127(11.7)$ & 0.232 \\
\hline TG (> 1.7 mmol/L) & $3(12.0)$ & $186(17.2)$ & 0.496 \\
\hline $\mathrm{HDL}-\mathrm{C}(<1.1 \mathrm{mmol} / \mathrm{L})$ & $12(48.0)$ & $435(40.2)$ & 0.430 \\
\hline LDL-C (> $3.37 \mathrm{mmol} / \mathrm{L})$ & $2(8.0)$ & $148(13.7)$ & 0.413 \\
\hline VLDL (>0.78 $\mathrm{mmol} / \mathrm{L})$ & $2(8.0)$ & $181(16.7)$ & 0.246 \\
\hline $\mathrm{Na}+(<135 \mathrm{mmol} / \mathrm{L})$ & $13(52.0)$ & $320(29.5)$ & $0.015^{\star}$ \\
\hline $\mathrm{K}+(\mathrm{mmol} / \mathrm{L})$ & & & 0.772 \\
\hline $3.5-5.5$ & $24(96.0)$ & $1002(92.5)$ & \\
\hline$<3.5$ & $1(4.0)$ & $70(6.5)$ & \\
\hline
\end{tabular}




\begin{tabular}{|c|c|c|c|}
\hline Variables & $\begin{array}{l}\text { Number (\%) of } \\
\text { SSI }(n=25)\end{array}$ & Number $(\%)$ of non-SSI $(n=1083)$ & $P$ \\
\hline$>5.5$ & $0(0.0)$ & $11(1.0)$ & \\
\hline $\mathrm{CL}-(\mathrm{mmol} / \mathrm{L})$ & & & 0.151 \\
\hline $99-110$ & $18(72.0)$ & $929(85.8)$ & \\
\hline$<99$ & $6(24.0)$ & $135(12.5)$ & \\
\hline$>110$ & $1(4.0)$ & $19(1.8)$ & \\
\hline TCO2 (mmol/L) & & & 0.475 \\
\hline $20-30$ & $25(100.0)$ & $1022(94.4)$ & \\
\hline$<20$ & $0(0.0)$ & $17(1.6)$ & \\
\hline$>30$ & $0(0.0)$ & $44(4.1)$ & \\
\hline GLU (> $6.1 \mathrm{mmol} / \mathrm{L})$ & $9(36.0)$ & $373(34.4)$ & 0.871 \\
\hline UREA (> 8 mmol/L) & $0(0.0)$ & $74(6.8)$ & 0.176 \\
\hline UA (> upper limit) & $1(4.0)$ & $85(7.8)$ & 0.477 \\
\hline WBC $\left(>10^{*} 10^{9} / L\right)$ & $15(60.0)$ & $344(31.8)$ & $0.003^{*}$ \\
\hline NEUT $\left(1.8-6.3 * 10^{9} / L\right)$ & & & 0.281 \\
\hline $1.8-6.3$ & $9(36.0)$ & $556(51.3)$ & \\
\hline$<1.8$ & $0(0.0)$ & $6(0.6)$ & \\
\hline$>6.3$ & $16(64.0)$ & $521(48.1)$ & \\
\hline $\operatorname{LYM}\left(<1.1 * 10^{9} / \mathrm{L}\right)$ & $5(20.0)$ & $303(28.0)$ & 0.379 \\
\hline MON $\left(>0.6 * 10^{9} / \mathrm{L}\right)$ & $15(60.0)$ & $658(60.8)$ & 0.939 \\
\hline $\mathrm{RBC}<$ lower limit & $17(68.0)$ & $436(40.3)$ & $0.005^{\star}$ \\
\hline HGB < lower limit & $21(84.0)$ & $587(54.2)$ & $0.003^{*}$ \\
\hline HCT < lower limit & $22(88.0)$ & $675(62.3)$ & $0.009 *$ \\
\hline MCV (fL) & & & 0.365 \\
\hline $82-100$ & $25(100.0)$ & $1002(92.5)$ & \\
\hline$<82$ & $0(0.0)$ & $40(3.7)$ & \\
\hline$>100$ & $0(0.0)$ & $41(3.8)$ & \\
\hline
\end{tabular}




\begin{tabular}{|c|c|c|c|}
\hline Variables & $\begin{array}{l}\text { Number (\%) of } \\
\text { SSI }(n=25)\end{array}$ & Number $(\%)$ of non-SSI $(n=1083)$ & $P$ \\
\hline $\mathrm{MCH}(\mathrm{pg})$ & & & 0.564 \\
\hline $27-34$ & $24(96.0)$ & $990(91.4)$ & \\
\hline$<27$ & $0(0.0)$ & $47(4.3)$ & \\
\hline$>34$ & $1(4.0)$ & $46(4.2)$ & \\
\hline $\mathrm{MCHC}(\mathrm{g} / \mathrm{L})$ & & & 0.423 \\
\hline $316-354$ & $23(92.0)$ & $1008(93.1)$ & \\
\hline$<316$ & $0(0.0)$ & $32(3.0)$ & \\
\hline$>354$ & $2(8.0)$ & $43(4.0)$ & \\
\hline PDW (\%) & & & 0.557 \\
\hline $12-18.1$ & $21(84.0)$ & $945(87.3)$ & \\
\hline$<12$ & $4(16.0)$ & $116(10.7)$ & \\
\hline$>18.1$ & $0(0.0)$ & $22(2.0)$ & \\
\hline D-Dimer (>0.5 mg/L) & $20(80.0)$ & $650(60.0)$ & $0.043^{*}$ \\
\hline AG (mmol/L) & & & $0.024^{*}$ \\
\hline $8-16$ & $16(64.0)$ & $854(78.9)$ & \\
\hline$<8$ & $7(28.0)$ & $212(19.6)$ & \\
\hline$>16$ & $2(8.0)$ & $17(1.6)$ & \\
\hline OSM $<260 \mathrm{mOsm} / \mathrm{L}$ & $6(24.0)$ & $104(9.6)$ & $0.017 *$ \\
\hline $\mathrm{CA}(\mathrm{mmol} / \mathrm{L})$ & & & 0.480 \\
\hline $2.11-2.52$ & $17(68.0)$ & $822(75.9)$ & \\
\hline$<2.11$ & $8(32.0)$ & $246(22.7)$ & \\
\hline$>2.52$ & $0(0.0)$ & $15(1.4)$ & \\
\hline $\mathrm{P}$ (mmol/L) & & & $0.027 *$ \\
\hline $0.85-1.51$ & $17(68.0)$ & $932(86.1)$ & \\
\hline$<0.85$ & $2(8.0)$ & $53(4.9)$ & \\
\hline$>1.51$ & $6(24.0)$ & $98(9.0)$ & \\
\hline $\mathrm{Mg}$ (mmol/L) & & & $0.008^{*}$ \\
\hline
\end{tabular}




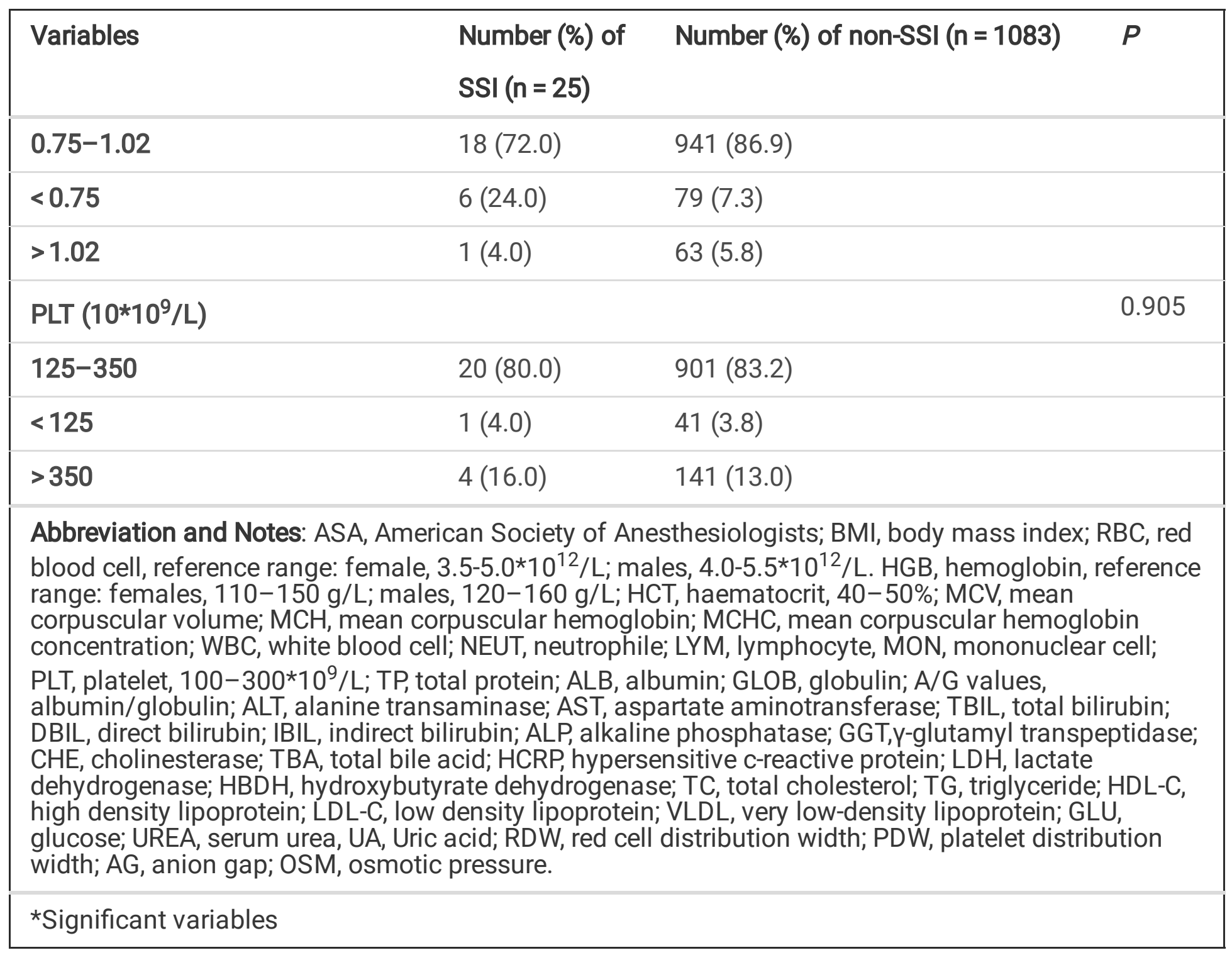

The multivariate analysis results showed that fracture type (Schartzker $\mathbb{Q}-\nabla)(p<0.001, \mathrm{OR}=8.129)$, bone grafting $(p=0.002)$, autograft $(p=0.001, \mathrm{OR}=6.380)$, allograft $(p=0.048, \mathrm{OR}=3.215)$, white blood cell ( $>$ $\left.10 * 10^{9} / \mathrm{L}\right)(p=0.044, \mathrm{OR}=2.498)$, aspartate aminotransferase $(>40 \mathrm{U} / \mathrm{L})(p<0.001, \mathrm{OR}=5.500)$ and anion gap $(>16 \mathrm{mmol} / \mathrm{L})(p=0.040, \mathrm{OR}=8.194)$ were identified to be associated with SSI. (Table 3$)$ 
Table 3

Multivariate analysis of factors associated with SSI after ORIF of closed tibial plateau fracture

\begin{tabular}{|c|c|c|c|c|}
\hline Variables & OR & 95\% Cl (lower limit) & 95\% Cl (upper limit) & $P$ \\
\hline Preoperative duration & 2.282 & 0.880 & 5.915 & 0.090 \\
\hline \multicolumn{4}{|l|}{ Bone grafting(yes) } & $0.002^{*}$ \\
\hline Autograft & 6.380 & 2.155 & 18.886 & $0.001^{*}$ \\
\hline Allograft & 3.215 & 1.009 & 10.247 & $0.048 *$ \\
\hline Operative duration (minutes) & 3.544 & 0.958 & 13.108 & 0.058 \\
\hline Fracture type (Schartzker $₫-\nabla)$ & 8.129 & 2.961 & 22.319 & $0.000 *$ \\
\hline AST (> $40 \mathrm{U} / \mathrm{L})$ & 5.500 & 2.191 & 13.807 & $0.000 *$ \\
\hline WBC $\left(>10 * 10^{9} / L\right)$ & 2.498 & 1.025 & 6.092 & $0.044^{*}$ \\
\hline AG (mmol/L) & & & & 0.078 \\
\hline$<8$ & 1.878 & 0.694 & 5.082 & 0.214 \\
\hline$>16$ & 8.194 & 1.101 & 60.980 & $0.040 *$ \\
\hline \multicolumn{5}{|c|}{ Abbreviation and Notes: AST, aspartate aminotransferase; WBC, white blood cell; AG, anion gap. } \\
\hline *Significant variables & & & & \\
\hline
\end{tabular}

\section{Discussion}

The incidence of SSI after ORIF varied according to different study designs and definitions of SSI. In this study, we designed it as prospective, with the purpose of better solving this problem and obtaining more reliable conclusions. This study showed that the overall incidence of SSI was $2.3 \%$ after ORIF of closed tibial plateau fractures in adults. Independent risk factors included bone grafting (autograft, allograft),

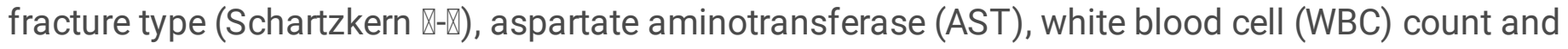
anion gap $(A G)$.

We had come to a conclusion that fracture type (Schartzker $\rrbracket-\rrbracket)$ was an important predictor of SSI after

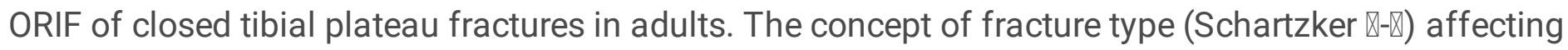
the SSI rate after ORIF has been well studied in previous investigations[11-13]. Morris et al investigated 302 patients undergoing ORIF of tibial plateau fractures, and observed a deep infection rate of $22.3 \%$,

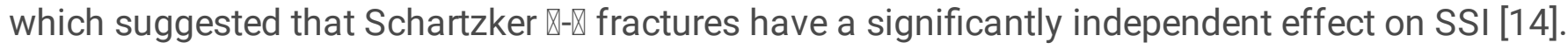

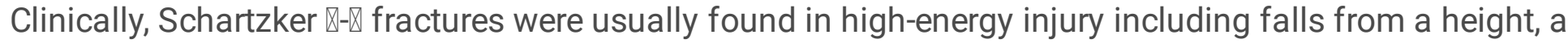
traffic accident, and a sports injury[11]. Although few previous studies had directly quantified this observed relationship, the level of fracture classification could reflect the severity of soft tissue injury to a certain extent $[15,16]$. In addition, we theorize that fracture type (Schartzker $\mathbb{\otimes}-\mathbb{Z}$ ) probably meant the 
greater technical difficulty, prolonged operative time and extended exposure of the wound, all of which might increase the chance of bacterial colonization and result in a higher incidence of SSI [17].

The tibial plateau fracture often was accompanied by compression of the fracture segments and collapse of the articular surface, which generally required bone grafting to restore articular surface and maintain internal fixation until bone union. At the present study, autograft and allograft were used in $10.9 \%(121 / 1108)$ and $10.6 \%(117 / 1108)$ of the patients, and the incidence of SSI among them were $6.6 \%(8 / 121)$ and $4.3 \%(5 / 117)$, which were consistent with previously reported figures. In a retrospective of 198 patients undergoing surgery of tibial plateau fracture, Bagherifard et al [18] found the complication rate of autograft and allograft was comparable, and they compared the SSI rate of autograft $(4.3 \%, 1 / 23)$ and allograft $(3.4 \%, 2 / 58)$. Lee et al.[19] analyzed the data from $1,303,347$ patients who underwent primary bone grafting and the infection rate was $3.05 \%$, demonstrating a higher SSI incidence rate in patients who received autologous bone grafts $(6.0 \%, 4909 / 81984)$ than those who received allograft grafts $(2.6 \%, 31330 / 1201359)$. The causes of postoperative infection caused by autologous bone grafting are related to the increase of surgical site, the extension of operation time and the increase of blood loss[20]. It is suggested that, there are two common causes of increased risk of infection after allograft. The first was unknown infection of the donor, and contamination during acquisition or processing; the second was delayed vascular penetration, slow bone formation, and high bone resorption rate after surgery[21]. Contrary to previous studies, the infection rate of autografts was higher than that of allografts $(O R=6.380$ vs $O R=3.215)$. Although autograft was considered the gold standard for bone grafting, there were some disadvantages, such as the need to increase the surgical site, and duration of surgery and intraoperative blood loss, which might increase the risk of infection[22].

Elevated WBC (white blood cells) counts in trauma patients had been well studied in previous studies. Several studies had explored the prognostic value of white blood cell counts at admission and continuous white blood cell counts during hospitalization in predicting infection during orthopedic surgery[23-25]. In previous studies, postoperative white blood cell count was more likely to be used to predict postoperative infection[26,27]. We concluded that preoperative WBC counts was an independent risk factor for postoperative infection. It is well known that the increase of WBC count in trauma patients before surgery is caused by the physiological stress of the body's immune system[28-30]. We speculated that the increase in postoperative infection might be related to immune system disorders following trauma. The innate immune system is not only activated by pathogen-associated molecular patterns, but also by trauma, such as fractures or multiple injuries[31, 32]. In this case, so-called risk-associated molecular patterns have been identified as danger signals that mediate early post-traumatic inflammatory responses[33], leading to infectious complications. Therefore, we need to pay enough attention to these patients with an elevated preoperative WBC count, observe the wound regularly and carefully after the operation.

Fractures usually involve soft tissue damage, and consequently, local tissue hypoxia and acidosis in tissue environment will be caused [34], Serum skeletal muscle enzymes are markers of the functional state of muscle tissue, and aspartate aminotransferase (AST) is one of the most useful serum markers of 
muscle injury[35]. Injury of muscle tissue after fracture can lead to elevated serum AST. In addition, the local tissue environment is in the state of metabolic acidosis after organism injury. With the aggravation of metabolic acidosis, the serum anion gap increases with the increase of serum lactic acid level[36]. Even in some studies, higher serum AG was independently associated with higher levels of inflammatory biomarkers in healthy samples from the general population[37]. In our study, high preoperative serum AST and AG were both independent risk factors for SSI after ORIF of tibial plateau fractures. Therefore, we should pay enough attention to soft tissue injuries and allowed sufficient soft tissue repair via delaying the definite operation by use of temporary external fixation or minimally invasive surgery, to reduce or even avoid SSI.

Although the design of this study was prospective, several limitations had to be mentioned. First, there were several orthopedic trauma surgeons involved in the treatment of tibial plateau fractures, each with their own judgment on the operation. Second, some specific variables, such as smoking status and alcohol consumption, could not be accurately quantified. In addition, some patients might be unwilling to tell us about these bad habits and choose to withhold information. Medical comorbidity information mainly relied on patients' self-report, and some patients might lack a clear knowledge. Third, it should be pointed out that our hospital was a first-level trauma center and patients might be more severely injured, therefore, the SSI identified in this study could be less representative.

In summary, we observed 25 cases $(2.3 \%)$ of SSI in 1108 adult patients with close tibial plateau fractures.

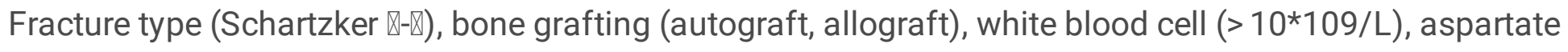
aminotransferase $(>40 \mathrm{U} / \mathrm{L})$, and anion gap $(>16 \mathrm{mmol} / \mathrm{L})$ were identified as independent risk factors for SSI. We should pay enough attention to patients who carried one or more of these preoperative factors and adopt more reasonable treatment strategies to avoid the occurrence of SSI.

\section{Abbreviations}

SSI: surgical site infection; ORIF: open reduction and internal fixation; SSIOS: Surgical Site Infection in Orthopaedic Surgery

\section{Declarations}

\section{Acknowledgements}

We appreciate the contribution of all patients, their families, the investigators, and the medical staff. We are grateful to all authors.

\section{Authors' contributions}

Ying-ze Zhang designed the study; Jun-yong Li, Jun-zhe Zhang, Kuo Zhao, Hong-yu Meng and Zhu-cheng Jin searched relevant studies; Yan-bin Zhu, and Jiang-tao Ma analyzed and interpreted the data; Jun-yong Li and Yan-bin Zhu wrote the manuscript and Ying-ze Zhang approved the final version of the manuscript. 


\section{Funding}

There is no funding received.

\section{Availability of data and materials}

The data and materials contributing to this article may be made available upon request by sending an email to the first author.

\section{Ethics approval and consent to participate}

The ethics committee of our hospital approved the SSIOS (NO 2014-015-1), and all the participants had written the informed consent.

\section{Consent for publication}

Consent to publish was obtained from the patient detailed in this study.

\section{Competing interests}

The authors declare no conflict of interests.

\section{References}

1. Zhang Y. Clinical epidemiology of orthopedic trauma: Thieme; 2012.

2. Jiwanlal A, Jeray KJ. Outcome of posterior tibial plateau fixation. J Knee Surg. 2016;29:034-9.

3. Khatri K, Sharma V, Goyal D, Farooque K. Complications in the management of closed high-energy proximal tibial plateau fractures. Chin J Traumatol. 2016;19:342-7.

4. Kugelman DN, Qatu AM, Strauss EJ, Konda SR, Egol KA. Knee stiffness after tibial plateau fractures: predictors and outcomes (OTA-41). J Orthop Trauma. 2018;32:e421-e7.

5. Shao J, Chang H, Zhu Y, Chen W, Zheng Z, Zhang H, et al. Incidence and risk factors for surgical site infection after open reduction and internal fixation of tibial plateau fracture: a systematic review and meta-analysis. Int J Surg. 2017;41:176-82.

6. Li J, Zhu Y, Liu B, Dong T, Chen W, Zhang Y. Incidence and risk factors for surgical site infection following open reduction and internal fixation of adult tibial plateau fractures. Int Orthop. 2018;42:1397-403.

7. Ma Q, Aierxiding A, Wang G, Wang C, Yu L, Shen Z. Incidence and risk factors for deep surgical site infection after open reduction and internal fixation of closed tibial plateau fractures in adults. Int Wound J. 2018;15:237-42.

8. Zhu Y, Liu S, Zhang X, Chen W, Zhang Y. Incidence and risks for surgical site infection after adult tibial plateau fractures treated by ORIF: a prospective multicentre study. Int Wound J. 2017;14:9828. 
9. Yeap JS, Lim JW, Vergis M, Yeung PSA, Singh H. Prophylactic Antibiotics in Orthopedic Surgery: Guidelines and Practice. Med J Malaysia. 2006;61:181-8.

10. Horan TC, Gaynes RP, Martone WJ, Jarvis WR, Emori TG. CDC definitions of nosocomial surgical site infections, 1992: a modification of CDC definitions of surgical wound infections. Am J Infect Control. 1992;13:606-8.

11. Ruffolo MR, Gettys FK, Montijo HE, Seymour RB, Karunakar MA. Complications of High-Energy Bicondylar Tibial Plateau Fractures Treated With Dual Plating Through 2 Incisions. J Orthop Trauma. 2015;29:85-90.

12. Paryavi E, Stall A, Gupta R, Scharfstein DO, Castillo RC, Zadnik M, et al. Predictive model for surgical site infection risk after surgery for high-energy lower-extremity fractures: Development of the Risk of Infection in Orthopedic Trauma Surgery Score. J Trauma. 2013;74:1521-7.

13. Henkelmann R, Frosch K-H, Glaab R, Lill H, Schoepp C, Seybold D, et al. Infection following fractures of the proximal tibia - a systematic review of incidence and outcome. BMC Musculoskelet Disord. 2017;18:481.

14. Morris BJ, Unger RZ, Archer KR, Mathis SL, Obremskey WT. Risk Factors of Infection After ORIF of Bicondylar Tibial Plateau Fractures. J Orthop Trauma. 2013;27:196-200.

15. Teeny SM, Wrss DA. Open Reduction and Internal Fixation of Tibial Plafond Fractures: Variables Contributing to Poor Results and Complications. Clin Orthop Relat Res. 1993;292:108-17.

16. Young M. Complications of internal fixation of tibial plateau fractures. Orthop Rev. 1994;23.

17. Menghi A, Mazzitelli G, Marzetti E, Barberio F, D’Angelo E, Maccauro G. Complex tibial plateau fractures: a retrospective study and proposal of treatment algorithm. Injury. 2017;48:1-6.

18. Bagherifard A, Ghandhari $H$, Jabalameli $M$, Rahbar $M$, Hadi $H$, Moayedfar $M$, et al. Autograft versus allograft reconstruction of acute tibial plateau fractures: a comparative study of complications and outcome. Eur J Orthop Surg Traumatol. 2017;27:665-71.

19. Lee F-H, Shen P-C, Jou I-M, Li C-Y, Hsieh J-L. A population-based 16-year study on the risk factors of surgical site infection in patients after bone grafting: a cross-sectional study in Taiwan. Medicine (Baltimore). 2015;94.

20. AP AHSGTG, M SRS. R, et al. Autologous Iliac Bone Graft Compared with Biphasic Hydroxyapatite and Calcium Sulfate Cement for the Treatment of Bone Defects in Tibial Plateau Fractures: A Prospective, Randomized, Open-Label, Multicenter Study. J Bone Joint Surg Am. 2020;102:179-93.

21. R Z, A S, M B, M K, M K. Infection in Bone Allograft Transplants. Exp Clin Transplant. 2016;14:48490.

22. Egol KA, Nauth A, Lee M, Pape H-C, Watson JT, Borrelli J Jr. Bone grafting: sourcing, timing, strategies, and alternatives. J Orthop Trauma. 2015;29:10-S4.

23. Rainer T, Chan T, Cocks R. Do peripheral blood counts have any prognostic value following. trauma? Injury. 1999;30:179-85. 
24. Chang DC, Cornwell EE III, Phillips J, Paradise J, Campbell K. Early leukocytosis in trauma patients: what difference does it make? Curr Surg. 2003;60:632-5.

25. Lam SW, Leenen LP, van Solinge WW, Hietbrink F, Huisman A. Evaluation of hematological parameters on admission for the prediction of 7-day in-hospital mortality in a large trauma cohort. Clin Chem Lab Med. 2011;49:493-9.

26. Weng J, Brown CV, Rhee P, Salim A, Chan L, Demetriades D, et al. White blood cell and platelet counts can be used to differentiate between infection and the normal response after splenectomy for trauma: prospective validation. J Trauma. 2005;59:1076-80.

27. Suzuki S, Haga Y, Hashizume K, Murayama A, Ishikawa S, Takahashi A, et al. C-reactive protein, white blood cell and body temperature following cardiovascular surgery, as predicting factors of postoperative infection. Kyobu Geka. 2006;59:1146-53.

28. Landmann R, Müller F, Perini C, Wesp M, Erne P, Bühler F. Changes of immunoregulatory cells induced by psychological and physical stress: relationship to plasma catecholamines. Clin Exp Immunol. 1984;58:127.

29. Mills PJ, Goebel M, Rehman J, Irwin MR, Maisel AS. Leukocyte adhesion molecule expression and T cell naive/memory status following isoproterenol infusion. J Neuroimmunol. 2000;102:137-44.

30. Kühlwein EC, Irwin MR, Ziegler MG, Woods VL, Kennedy B, Mills PJ. Propranolol affects stressinduced leukocytosis and cellular adhesion molecule expression. Eur J Appl Physiol. 2001;86:13541.

31. Stahel PF, Smith WR, Moore EE. Role of biological modifiers regulating the immune response after trauma. Int J Care Injured. 2007;38:1409-22.

32. Neher MD, Weckbach S, Flierl MA, Huber-Lang MS, Stahel PF. Molecular mechanisms of inflammation and tissue injury after major trauma-is complement the "bad guy"? J Biomed Sci. 2011;18:90.

33. Matzinger P. The Danger Model: A Renewed Sense of Self. Science. 2002;296:301-5.

34. Tull F Jr. B. Soft-tissue injury associated with closed fractures: evaluation and management. J Am Acad Orthop Surg. 2003;11:431-8.

35. Brancaccio P, Lippi G, Maffulli N. Biochemical markers of muscular damage. Clin Chem Lab Med. 2010;48:757-67.

36. Berkman M, Ufberg J, Nathanson LA, Shapiro NI. Anion gap as a screening tool for elevated lactate in patients with an increased risk of developing sepsis in the emergency department. J Emerg Med. 2009;36:391-4.

37. Ahn SY, Ryu J, Baek SH, Han JW, Lee JH, Ahn S, et al. Serum anion gap is predictive of mortality in an elderly population. Exp Gerontol. 2014;50:122-7.

\section{Figures}




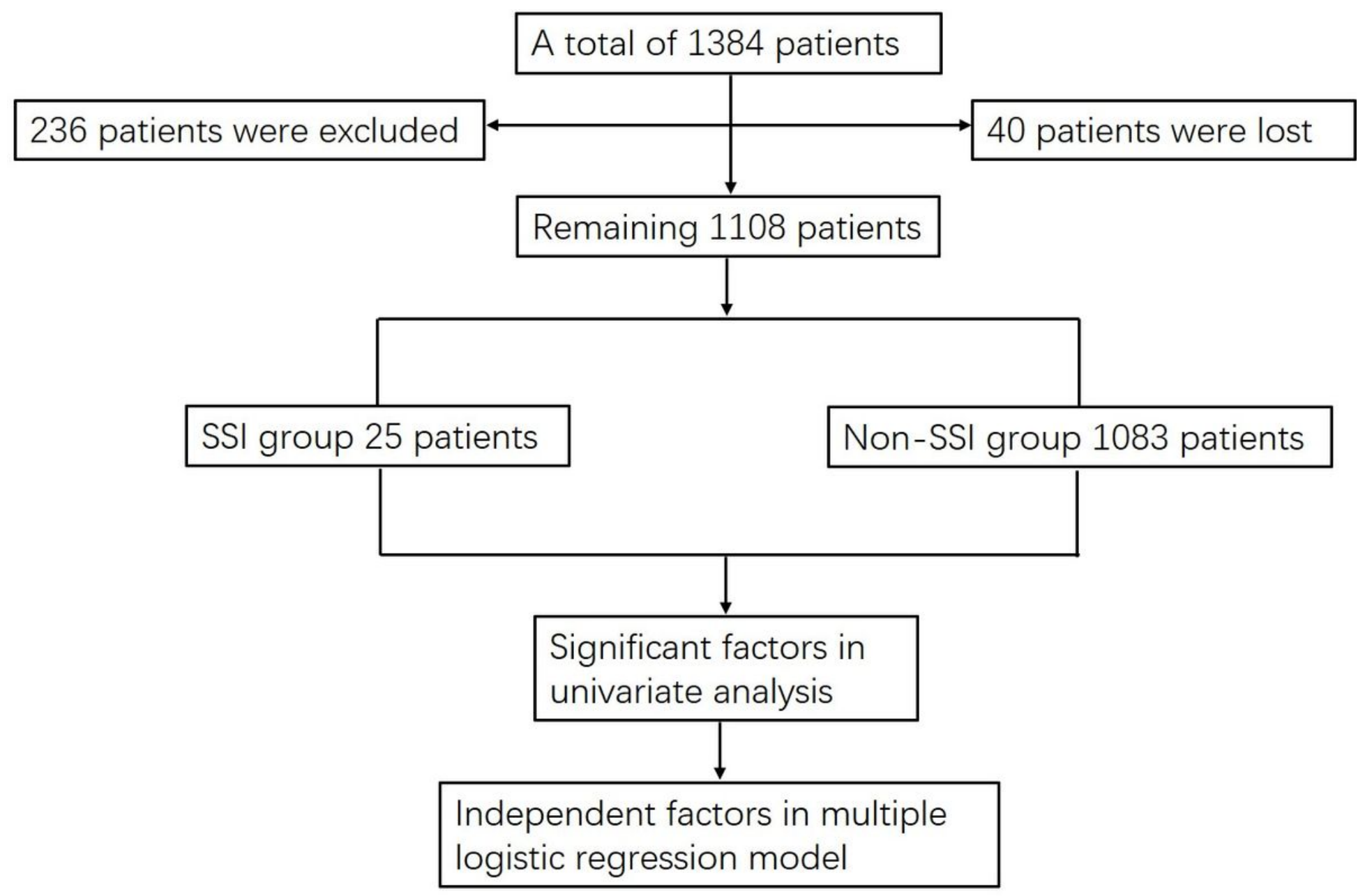

Figure 1

Patient flowchart. 